\title{
Sprachhygiene in der Pneumologie
}

Mir fallen immer wieder 2 falsch verwendete Begriffe auf:

1. Exazerbation - laut Fremdwörter-Duden: Wiederaufleben einer Erkrankung.

Der Begriff wird u. a bei dem Krankheitsbild einer COPD benutzt (chronisch obstruktive Lungenerkrankung), um eine akute Verschlechterung des Krankheitsbildes auszudrücken, d.h. Exazerbation einer COPD. Leider wird dem sowieso Kurzzeitigkeit ausdrückenden Begriff immer wieder redundant das Wort „akut“ hinzugefügt - eine Exazerbation ist immer „akut“ (ähnlich wie der medizinische Begriff „akuter“ Herzinfarkt - ich kenne keinen „chronischen“ Infarkt).

2. Antibiose - laut Fremdwörter-Duden: die hemmende oder abtötende Wirkung von Stoffwechselprodukte bestimmter Mikroorganismen. Gegenteil: Symbiose.

Antibiose wird leider fälschlich im medizinischen Sprachgebrauch für eine Antibiotikatherapie eingesetzt, z. B. als Antibiose benutzten wir ein Cephalosporin. Wenn man sich das Gegenteil des Begriffes vor Augen hält, merkt man, wie schräg diese Benutzung klingt.

Ich habe als ehemaliger OA einer pneumologischen Klinik meine Assistenten immer wieder auf diese medizinischen Torheiten hingewiesen. Leider verbreitet sich der falsche Sprachgebrauch wie Unkraut.

Dr. med. Frank Simm, Dortmund

fsimm@arcor.de 